\title{
A Post-Treatment Method to Enhance the Property of Aerosol Jet Printed Electric Circuit on 3D Printed Substrate
}

\author{
Bing Wang ${ }^{1,2,3}$, Haining Zhang ${ }^{1}$, Joon Phil Choi ${ }^{1,4}$, Seung Ki Moon ${ }^{1,4, * \mathbb{C}}$, Byunghoon Lee ${ }^{5}$ \\ and Jamyeong Koo ${ }^{5}$ \\ 1 School of Mechanical and Aerospace Engineering, Nanyang Technological University, \\ Singapore 639798, Singapore; wangbing@e.ntu.edu.sg (B.W.); m160034@e.ntu.edu.sg (H.Z.); \\ joonphil.choi@ntu.edu.sg (J.P.C.) \\ 2 Strong-Field and Ultrafast Photonics Lab, Key Laboratory of Trans-Scale Laser Manufacturing Technology, \\ Ministry of Education, Faculty of Materials and Manufacturing, Beijing University of Technology, \\ Beijing 100124, China \\ 3 Beijing Engineering Research Center of Laser Technology, Beijing University of Technology, \\ Beijing 100124, China \\ 4 Singapore Centre for 3D Printing, School of Mechanical and Aerospace Engineering, \\ Nanyang Technological University, Singapore 639798, Singapore \\ 5 Global Technology Center, Samsung Electronics Co., Ltd., Suwon 16677, Korea; \\ bh13.lee@samsung.com (B.L.); jamyeong.koo@samsung.com (J.K.) \\ * Correspondence: skmoon@ntu.edu.sg; Tel.: +65-6790-5599
}

Received: 14 October 2020; Accepted: 7 December 2020; Published: 8 December 2020

\begin{abstract}
Aerosol jet printing of electronic devices is increasingly attracting interest in recent years. However, low capability and high resistance are still limitations of the printed electronic devices. In this paper, we introduce a novel post-treatment method to achieve a high-performance electric circuit. The electric circuit was printed with aerosol jet printing method on an ULTEM substrate. The ULTEM substrate was fabricated by the Fused Deposition Modelling method. After post-treatment, the electrical resistance of the printed electric circuit was changed from $236 \mathrm{~m} \Omega$ to $47 \mathrm{~m} \Omega$ and the electric property was enhanced. It was found that the reduction of electric resistance was caused by surface property changes. Different surface analysis methods including scanning electron microscopy (SEM) and x-ray photoelectron spectroscopy (XPS) were used to understand the effectiveness of the proposed method. The results showed that the microsurface structure remained the same original structure before and after treatment. It was found that the surface carbon concentration was significantly increased after treatment. Detailed analysis showed that the C-C bond increased obviously after treatment. The change of electrical resistance was found to be limited to the material's surface. After polishing, the circuit resistance was changed back to its original value. As the electric circuit is the basic element of electric devices, the proposed method enables the fabrication of high performance devices such as capacitors, strain gauge, and other sensors, which has potential applications in many areas such as industrial, aerospace, and military usage.
\end{abstract}

Keywords: 3D printing; anti-high temperature; microelectronic device; sensor

\section{Introduction}

Direct writing is a widely used 3D printing method for electronic device fabrication due to its low-cost, high customization, and flexibility [1-3]. 3D printing or additive manufacturing is an advanced manufacturing technology developed in recent years, which is widely used in aerospace, defense, 
and other industries [4-6]. Materials are joined layer by layer through the process. Compared with the traditional manufacturing methods, direct writing is a simple and fast process of creating high precision features and customized components. There are various direct writing methods such as inkjet printing [3], screen printing [7] and aerosol jet printing [2]. Recently, there is an increasing number of research studies related to electric devices printed by direct writing technologies, such as the direct printing of supercapacitors [8], transistor circuits $[9,10]$, solar cells $[7,11]$, and organic light-emitting devices (OLEDs) [12].

Aerosol jet printing is a relatively new developed direct writing method [13-15]. It is a contactless printing method with high resolution, high flexibility, and enables printing on various substrates such as metals, semiconductors, and polymers. It was initially developed for the 3D printing of electronic circuitry and the printing resolution is typically up to $10 \mu \mathrm{m}[16,17]$. During the printing process, metal ink/electronic ink is accurately and precisely deposited onto the substrates through aerodynamic focusing [18]. Materials able to suspend in aerosol are compatible with this technique, besides metal inks, ceramics, polymers, carbon nanotubes, and biomaterials are also able to be deposited [17]. In general, it is most widely used for electronic circuit or device printing. Clifford et al. investigated the aerosol jet printed humidity sensor on pre-packaged integrated circuits. It shows a good response to humidity in the range of $40 \%$ to $80 \%$ [19]. Cantu et al. investigated the aerosol jet printed electrochemical sensors for protein detection. It shows the aerosol jet printed sensors can detect lower current density and has a lower deviation compared with screen-printed sensors [20]. Cao et al. reported that the aerosol jet printed carbon nanotube thin film transistor. The printed transistor shows high reliability and good performance up to 1000 cycles of bending test [21]. Maiwald et al. studied the functionality of strain gauge sensors fabricated using aerosol jet printing [22]. Zhao et al. reported the direct strain gauge printing by aerosol jet method on composite structures [23]. Rahman et al. investigated the aerosol jet printed strain sensors at high temperature up to $500{ }^{\circ} \mathrm{C}$, and the reliability and performance of the sensors were tested [24]. The quality of the aerosol jet printed device is of great importance in applications. However, in the current status, the low capability and high resistance are still limitations of the aerosol jet printed electronic devices [25]. Fundamental research works have investigated the quality of aerosol jet printed electric circuits $[17,26,27]$. Bourassa et al. reported a water vapor assisted sintering process. With the presence of $10 \mathrm{~g}$ water in oven during the sintering process, the resistivity of the aerosol jet printed circuit was found to be significantly reduced. It was shown that the reduction of resistivity was due to the larger connected area formed during the sintering process [28]. Efimov et al. investigated the effect of substrate temperature on the aerosol jet printing sintering process. To improve the conductivity, an optimized temperature of $200{ }^{\circ} \mathrm{C}$ was obtained [29]. Halonen et al. [30] optimized the sintering temperature to minimize the resistance. It was found that a strong endothermic reaction appeared at temperature range of $160^{\circ} \mathrm{C}$ to $210^{\circ} \mathrm{C}$, which indicated sintering via diffusion and partial melting without mass reduction. Hwang et al. [31] reported that the sintering temperature and time affected neck and pore growth which resulted in the specific resistance; the printed $\mathrm{Ag}$ nanoparticle ink after sintering at $250{ }^{\circ} \mathrm{C}$ for 50 min showed minimum specific resistance. Dana et al. proposed a novel intense pulsed light (IPL) sintering process for aerosol jet printed electric circuit. It was reported that the fresh printed layer could be solidified in milliseconds with IPL post-treatment, which has an advantage for polymer substrate printing [32]. Mahajan et al. studied the effect of the ratio of sheath gas flow rate to carrier gas flow rate (focusing ratio) on the printed quality. It was found that the line width decreased the focusing ratio, while line thickness increased when increasing the focusing ratio [26]. An analytical study was conducted by Binder et al. to identify the effect of process parameters and predict the printed line width [27]. Smith et al. investigated the effect of gas flow rate, focus ratio, and substrate temperature on aerosol jet printed line quality [17]. Zhang et al. proposed a hybrid machine learning method to optimize the printing parameter and determine the aerosol jet printing operation window [18]. Goh et al. studied the adhesiveness, conductivity, and wetting property of aerosol jet printed circuit. It was found that the adhesion could be increased with a plasma treatment before printing [33]. There is 
an increasing number of research studies focusing on the quality improvement of the printed circuit. However, most of the research is limited to optimization in processing parameters and the high resistance of the aerosol jet printed circuit is still not properly solved.

Compared with traditional fabricated silicon-based electronic devices, electronic devices fabricated on polymer substrates can maintain its electrical continuity in both the original state and under deformation. ULTEM is a high strength plastic with high temperature resistance, high chemical resistance, high dielectric strength, and extremely strong and stiff. It is widely used for electrical connectors, manifolds, medical components, and scientific parts. It has become a popular material for FDM 3D printing due to its stability and adhesive property [34-36]. ULTEM 9085 is a new commercial 3D printing material that can be used for aerospace applications [37].

In this paper, we introduce a novel post-treatment method for printing a high electrical performance circuit. Firstly, the electric circuit is printed by aerosol jet printing method on a FDM fabricated ULTEM 9085 substrate with optimized printing parameters. Then, the sample is treated for a high temperature and high humidity post process. After the treatment, the resistance of the electric circuit can be reduced significantly. SEM investigation is conducted for surface morphology analysis. Surface chemical analysis is performed with XPS analysis.

\section{Materials and Methods}

A $40 \mathrm{~mm} \times 20 \mathrm{~mm} \times 5 \mathrm{~mm}$ ULTEM 9085 substrate was fabricated by a Fortus $450 \mathrm{mc}$ machine from Stratasys (Eden Prairie, MN, USA). The machine build envelop was $406 \times 355 \times 406 \mathrm{~mm}$. The nozzle size was T16. Air gap and raster angle were $0 \mathrm{~mm}$ and $+45^{\circ} /-45^{\circ}$, respectively. The layer thickness was $0.254 \mathrm{~mm}$ with a contour width of $0.508 \mathrm{~mm}$. An Aerosol Jet 3D printer from Optomec ${ }^{\circledR}$ (Albuquerque, NM, USA) was employed to conduct the experiment. During the process, firstly the silver ink was atomized by the ultrasonic atomizer, then it was entrained in nitrogen gas carriers. The entrained ink aerosol was then delivered to the print head. In the print head, the ink aerosol was shaped and accelerated by sheath gas to the print nozzle. The aerosol droplet was deposited into the substrate and heated for solvent evaporation as presented in Figure 1. Silver nanoparticle ink (Clariant) diluted with DI water at a ratio of 1:1 was used for the experiment. The atomizer current was $0.3 \mathrm{~mA}$. The nozzle tip height was $3 \mathrm{~mm}$ with a diameter of $150 \mu \mathrm{m}$. Printing speed was set to be $1 \mathrm{~mm} / \mathrm{s}$ and the ink temperature was fixed at $20^{\circ} \mathrm{C}$. The flow rate of carrier gas and sheath gas were set to 30 and $45 \mathrm{sccm}$ (standard cubic centimeters per minute), respectively. The printed line width was $40 \mu \mathrm{m}$ with an overlap of $25 \%$. The printed layer was fixed at 3 . The thickness of each printed layer is measured to be around $3 \mu \mathrm{m}$. After printing, the sample was sintered for $2 \mathrm{~h}$ at $200^{\circ} \mathrm{C}$. Aerosol jet printing is a complicated process and main process parameters affect the printing quality significantly. In this paper, all the process parameters were optimized with a hybrid method. Firstly, Latin hypercube sampling was applied to design the experiment, and then the printing quality was analyzed quantitatively with respect to the process parameters. After that, the optimal operating process window of aerosol jet printing was identified by a support vector machine approach. A detailed information of the optimization process can be found in Zhang, et al. [18].

The printed sample was then subjected to two types of post-processes: (1) Treatment A: a cycled treatment at $-40{ }^{\circ} \mathrm{C}$ to $85^{\circ} \mathrm{C}$ for 100 rounds and (2) Treatment B: high temperature treatment at $80{ }^{\circ} \mathrm{C}$ with high humidity $80 \%$ for $120 \mathrm{~h}$ as shown in Table 1 . The conductivity before and after treatment was measured. The surface structure and surface chemistry were investigated with SEM (5600LV, Jeol Asia Pte Ltd., Tokyo, Japan) and XPS (VG ESCALAB 220i-XL, Thermo Scientific, East Grinstead, West Sussex, UK). 


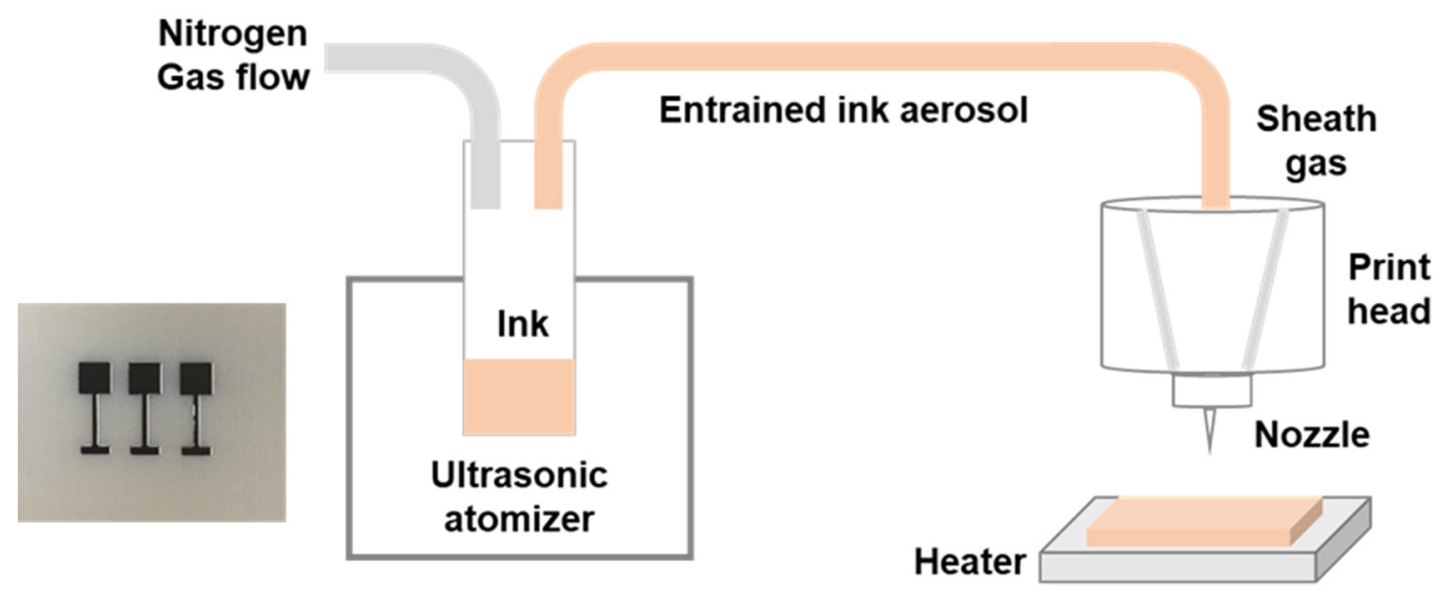

Figure 1. Illustration of the aerosol jet printing process and an image of the printed electronic circuit.

Table 1. Sample post-treatment methods.

\begin{tabular}{cc}
\hline Sample & Post-Treatment Method \\
\hline Original & NA (Stored in air) \\
Treatment A & $-40^{\circ} \mathrm{C}$ to $85^{\circ} \mathrm{C}$ for 100 cycles \\
Treatment B & $80^{\circ} \mathrm{C}, 80 \%$ humidity for $120 \mathrm{~h}$ \\
\hline
\end{tabular}

\section{Results and Discussion}

The 3D printed circuit is shown in Figure 1. The resistance of the original printed circuit from head to bottom was measured to be $236 \mathrm{~m} \Omega$, as demonstrated in Figure 2. The circuit resistance after treatment is shown in Table 2. As depicted in Table 2, after Treatment A (100 cycles post-treatment at temperature varied from $-40{ }^{\circ} \mathrm{C}$ to $\left.85^{\circ} \mathrm{C}\right)$, the resistance changed to $230 \mathrm{~m} \Omega$. After Treatment $\mathrm{B}(120 \mathrm{~h}$ post-treatment at $80^{\circ} \mathrm{C}$ with $80 \%$ humidity environment), the resistance reduced to $47 \mathrm{~m} \Omega$.

Table 2. Measured sample resistance before and after treatment.

\begin{tabular}{cc}
\hline Sample & Resistance $(\mathrm{m} \Omega)$ \\
\hline Original & $236 \pm 1.8$ \\
Treatment A & $230 \pm 1.8$ \\
Treatment B & $47 \pm 6.9$ \\
Silver film [38] & 45 \\
\hline
\end{tabular}

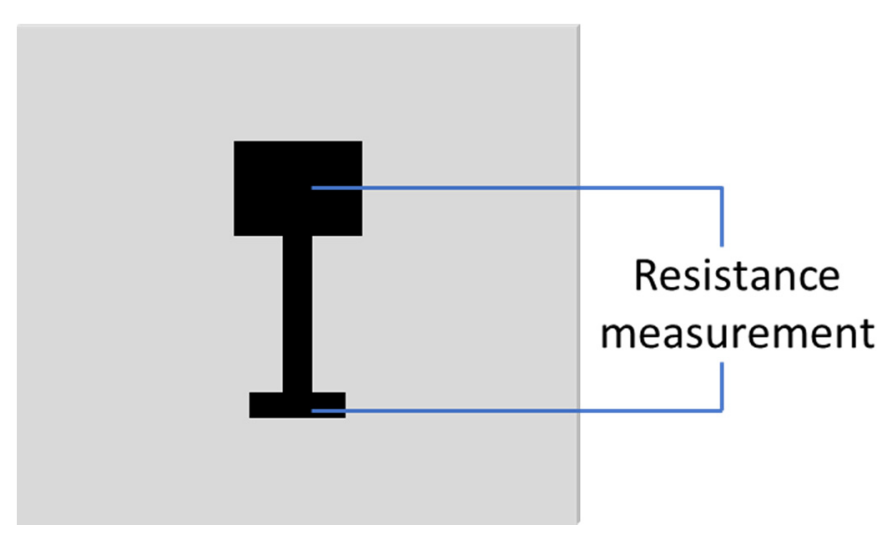

Figure 2. Demonstration of resistance measurement.

From Table 2, the reduction of resistance is significantly after treatment B. For aerosol jet printed electric circuits, the sample is normally considered as $2 \mathrm{D}$ structures with a few micrometers in 
thickness [39]. The reduction can be caused by the changes of surface property. To further investigate this phenomenon, surface properties including both surface chemistry and surface structure were examined before and after the treatment. The surface structure was investigated with SEM as shown in Figure 3. Figure 3a shows the SEM image of the original electric circuit surface, we can see the aerosol jet printed lines clearly along the ULTEM substrate. At a high magnification of $5000 \times$, the silver nanoparticles can be seen Figure 3a, right side. The surface structure after post-treatment at $80{ }^{\circ} \mathrm{C}$ with high humidity $80 \%$ for $120 \mathrm{~h}$ is shown in Figure $3 \mathrm{~b}$. The aerosol jet printed lines were still clear and at high magnification, and the nanoparticles were observed. From this figure, it is clear that there were no obvious microstructure changes found on the surface before and after treatment.

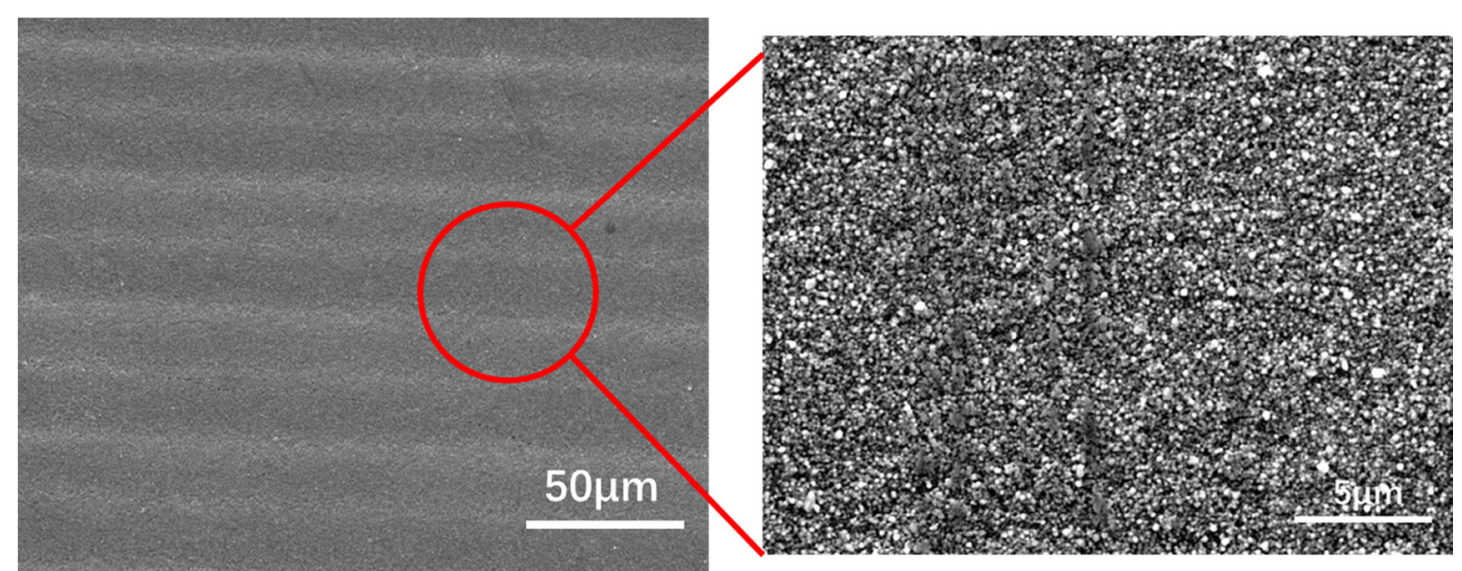

(a)

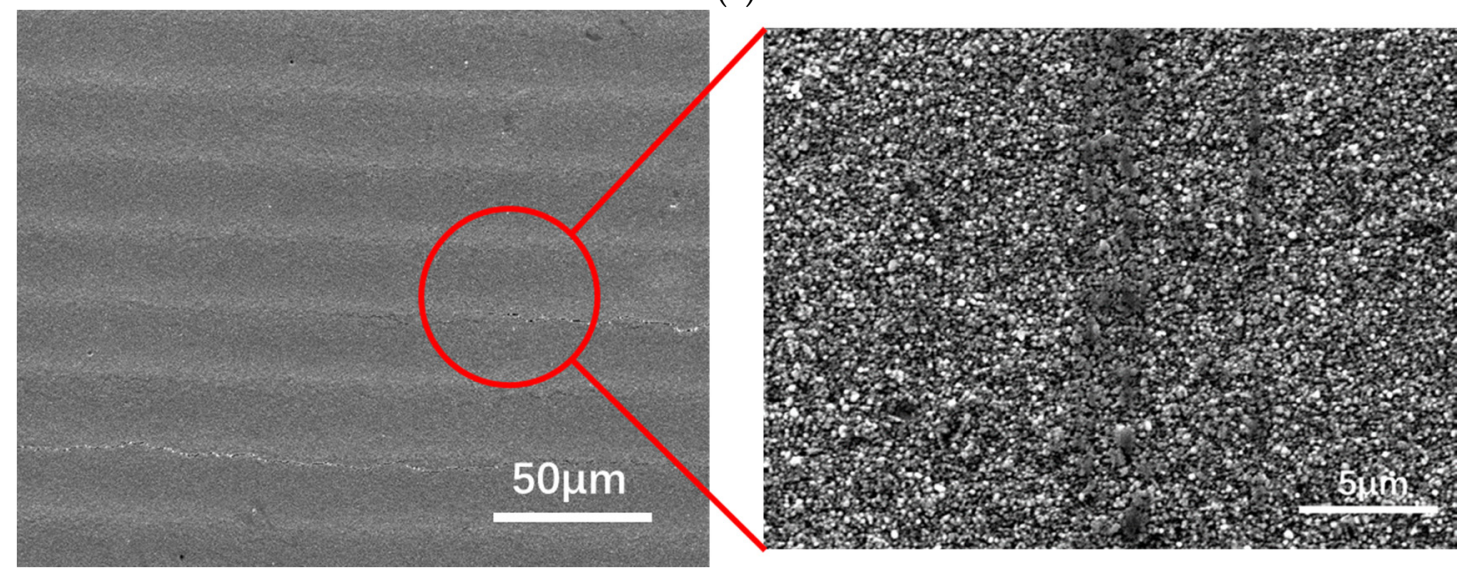

(b)

Figure 3. SEM image of (a) original sample and (b) sample after treatment at $80{ }^{\circ} \mathrm{C}$ and $80 \%$ humidity for $120 \mathrm{~h}$.

XPS analysis was conducted for surface chemistry investigation. Both wide scans of all the chemical elements and a narrow scan of the focused elements were performed. As shown in Table 3, there are four elements detected on the original surface: oxygen, silver, carbon, and chlorine. The original oxygen atomic concentration was measured to be $18.3 \%$ and after treatment, it increased to $23.4 \%$. The increase of oxygen indicates the oxidation on the surface. The original atomic concentration of silver was $38.9 \%$ and after treatment, the silver concentration reduced to $1.0 \%$. The decrease of silver concentration and increase of oxygen was possibly caused by the oxidation of silver. A detailed XPS analysis of silver element is shown in Figure 4. We can see the silver peak of original sample was around $368.2 \mathrm{eV}$, which is the peak of Ag metal. While after treatment, the silver peak shifted to $367.9 \mathrm{eV}$, which is the peak of $\mathrm{Ag}_{2} \mathrm{O}$. The detailed XPS analysis of silver element proved that the Ag metal was oxidized into $\mathrm{Ag}_{2} \mathrm{O}$ after the post-treatment. The high temperature and humidity environment may 
increase the oxidation speed of silver. Under a high humidity environment, a large amount of sliver cation is generated. The generated $\mathrm{Ag}^{+}$was reacted with hydroxide anion $\left(\mathrm{OH}^{-}\right)$in water, thus silver oxide was generated on the surface. The present of high temperature also rapid up the reaction speed. On the other hand, there are no obvious changes in the surface property of the sample after one month under room temperature and normal humidity. There are few amounts of chlorine detected on the original sample surface, and it was disappeared after treatment. These small amounts of chlorine may from the add-in material of the original silver dilute. After treatment, the sample surface was oxidized, and the carbon concentration increased significantly. The absorbed oxygen and carbon atom from the ambient environment may cover the small amount of chlorine elements, thus the chlorine elements are not detected after treatment. The hypothesis can be further proved by that after polishing, the chlorine elements were detected again.

Table 3. Atomic concentration of original sample and sample after treatment B.

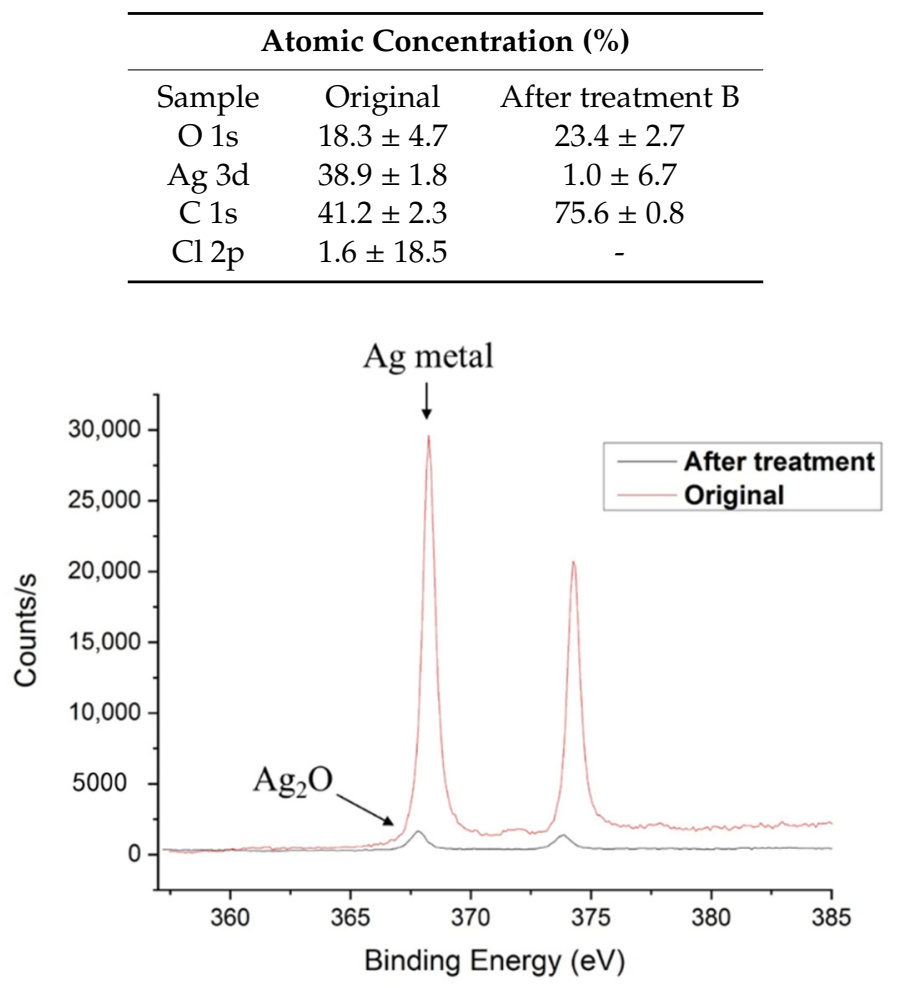

Figure 4. XPS analysis of silver element before and after treatment B, detailed data results are shown in Table 2 with relative errors.

Beside silver element, carbon element concentration was also changed significantly. From Table 3, the carbon atomic concentration increased from $41.2 \%$ to $75.6 \%$ after the post-treatment. Detailed XPS analysis for carbon element was conducted as shown in Table 4 and Figure 5a,b. As shown in Table 4, there are four peaks detected on the original sample: $\mathrm{C}-\mathrm{C}$ bond, $\mathrm{C}-\mathrm{O}$ bond, $\mathrm{C}-\mathrm{Cl}$ bond, and $\mathrm{O}-\mathrm{C}=\mathrm{O} / \mathrm{C}=\mathrm{O}$ bond. The $\mathrm{C}-\mathrm{C}$ bond atomic concentration increased from $42.3 \%$ to $54.4 \%$ after treatment. The $\mathrm{C}-\mathrm{O}$ bond decreased from $39.4 \%$ to 32 . $8 \%$. The $\mathrm{O}-\mathrm{C}=\mathrm{O} / \mathrm{C}=\mathrm{O}$ bond increased from $9.2 \%$ to $12.8 \%$. The $\mathrm{C}-\mathrm{Cl}$ bond was not detected after treatment. Since the total carbon concentration was increased significantly from $41.2 \%$ to $75.6 \%$, even though the bond atomic concentration decreased. Overall, they all increased compared with the original sample.

From the literature, when silver elements exposed to the atmosphere environment for a long term, oxidation and carbon contamination could be significant $[40,41]$. The amount of silver decreased significantly due to the increase of oxygen and carbon species on the sample surface. The increased carbon concentration and associated nonpolar carbon group formation decreased the surface free 
energy [42-46]. Generally, the absorption of carbon item from the environment occurs in the long term $[47,48]$, while the annealing process can accelerate the process in a short time $[45,48,49]$. There are several explanations for the increase of carbon concentration in the atmosphere including: the airborne hydrocarbon contamination from the atmosphere [45,46]; the absorption of other organic matters such as PDMS contamination from furnace [49], or other organic contamination like carboxylate from ambient air; the decomposition of carbon dioxide into carbon [43] with active magnetite; the partial deoxidation of the oxidized metal [50,51]. Further research has shown that the presence of common atmosphere gases such as $\mathrm{CO}_{2}, \mathrm{O}_{2}$, and $\mathrm{N}_{2}$ is not the main reason causing the carbon concentration changes, instead, the absorption of organic compounds seems to have a more significant influence on the carbon concentration $[52,53]$. These further supported with other research works showing that immersion or store in organic rich media will accelerate the carbon absorption process as in [44,54-56]. It seems the organic contamination during the annealing process could be the most possible reason. The mechanism of resistance reduction is still not clear. As reported in [28], the formation of larger connected silver ink areas during the sintering process with water could be a possible reason. The removal of organic capping agent at low temperature from the contacting gap could result in the resistivity reduction. On the other hand, it was reported by Matikainen et al. [40] that the carbon contamination from reaction with hydrocarbons in the atmosphere could result in the formation of thin carbon layers on the surface. Also, a graphene carbon layer was reported to form on metal surfaces under high temperature treatment with the presence of carbon sources $[57,58]$. Either hydrocarbon gases or solid polymer films can be the source for graphene layer generation on metal surfaces $[57,58]$.

In this case, the microscale SEM image was taken and showed no obvious changes. However, nanoscale changes of silver ink were not examined. The connected area in high a humidity environment may increase as reported in [28]. On the other hand, the increase of C-C bond on the surface could be the main reason causing the resistance reduction. A carbon layer was generated during the process thus enhanced the sample conductivity significantly (resistance dropped from $236 \mathrm{~m} \Omega$ to $47 \mathrm{~m} \Omega$ ). Besides the small amount of hydrocarbon gases in the air, ULTEM (polyetherimide), which contains a great amount of carbon atoms, can act as carbon sources as well. Since the printed ULTEM substrate has a porous structure, there are quite a number of un-melted and deposited powders attached to the substrate. Under high humidity and high temperature environment, the powder can be dissolved into the atmosphere. The pyrolysis occurred on the surface as time going on. In addition, the process can be catalyzed with the presence of silver nanoparticles [58]. On the other hand, the formed carbon layer can act as a protection to avoid further oxidization on the electric circuit surface.

To investigate the reduction of resistance on the material surface, the printed samples was polished with a 1200 grade sandpaper for $2 \mathrm{~s}$ to remove the outer surface. The SEM image of a polished sample is shown in Figure 6. After polishing, the printed lines disappeared, and the sample became flat. The resistance of the polished sample was measured to be $242 \mathrm{~m} \Omega$, which was near to the original sample resistance. This indicates the resistance reduction after treatment was mainly attributed to the thin layer at the surface of the printed sample. Table 5 shows the XPS analysis of the polished sample. After polishing, the carbon element concentration reduced to $46.1 \%$ and the atomic concentration of silver increased back to $39.5 \%$, which was quite near to the original value. The resistance recovered back after polishing could be due to the removal of the carbon layer on the surface.

Table 4. XPS analysis of carbon element.

\begin{tabular}{ccc}
\hline \multicolumn{3}{c}{ Atomic Concentration (\%) } \\
\hline Sample & Original & After treatment B \\
C 1s 284.8 (C-C) & $42.3 \pm 3.1$ & $54.4 \pm 1.2$ \\
C 1s 286.3 (C-O) & $39.4 \pm 3.1$ & $32.8 \pm 1.2$ \\
C 1s 287.6 (C-Cl) & $9.2 \pm 2.9$ & - \\
C 1s 288.6(O-C $=\mathrm{O} / \mathrm{C}=\mathrm{O})$ & $9.2 \pm 2.8$ & $12.8 \pm 1.0$ \\
\hline
\end{tabular}




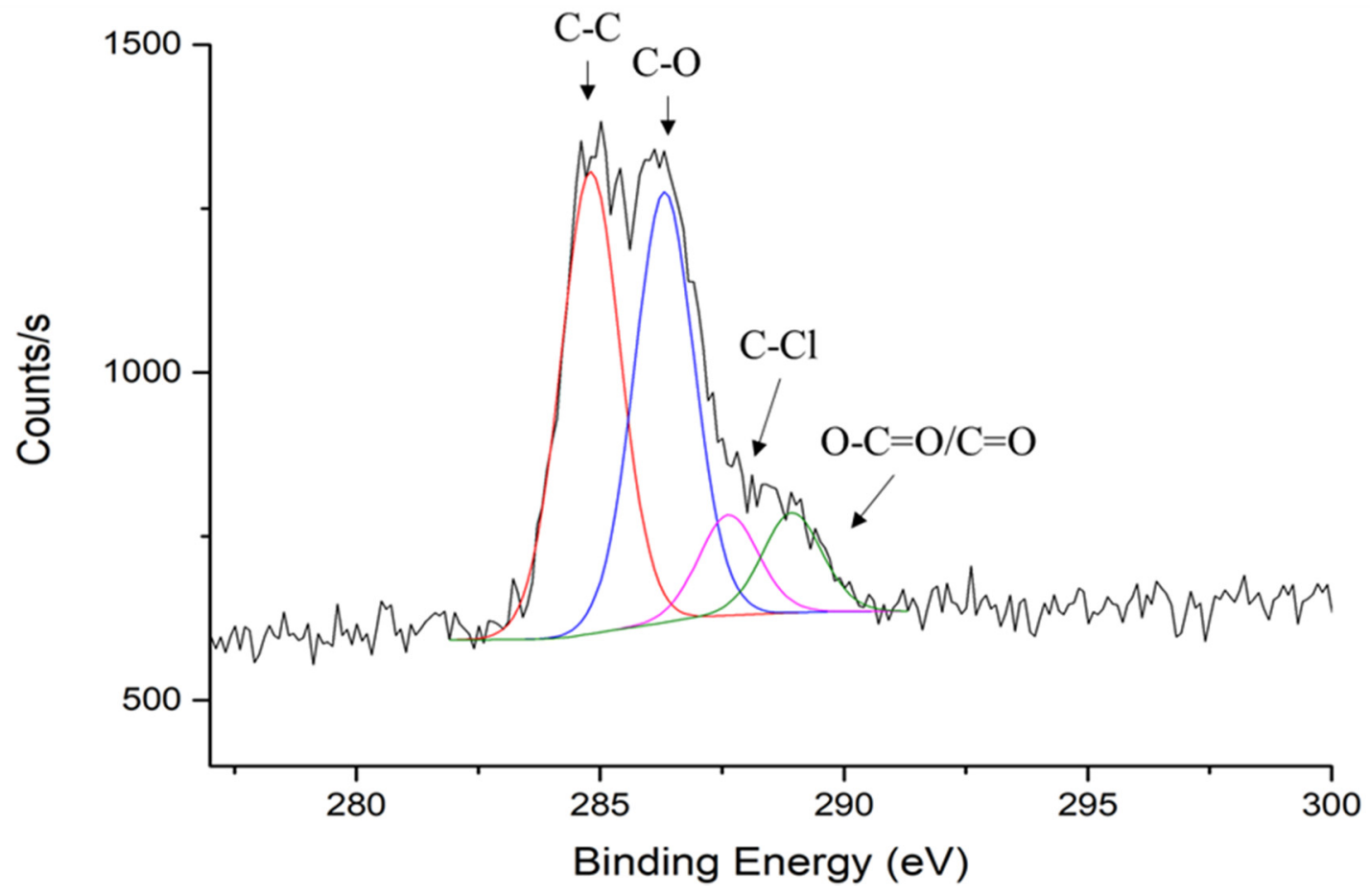

(a)

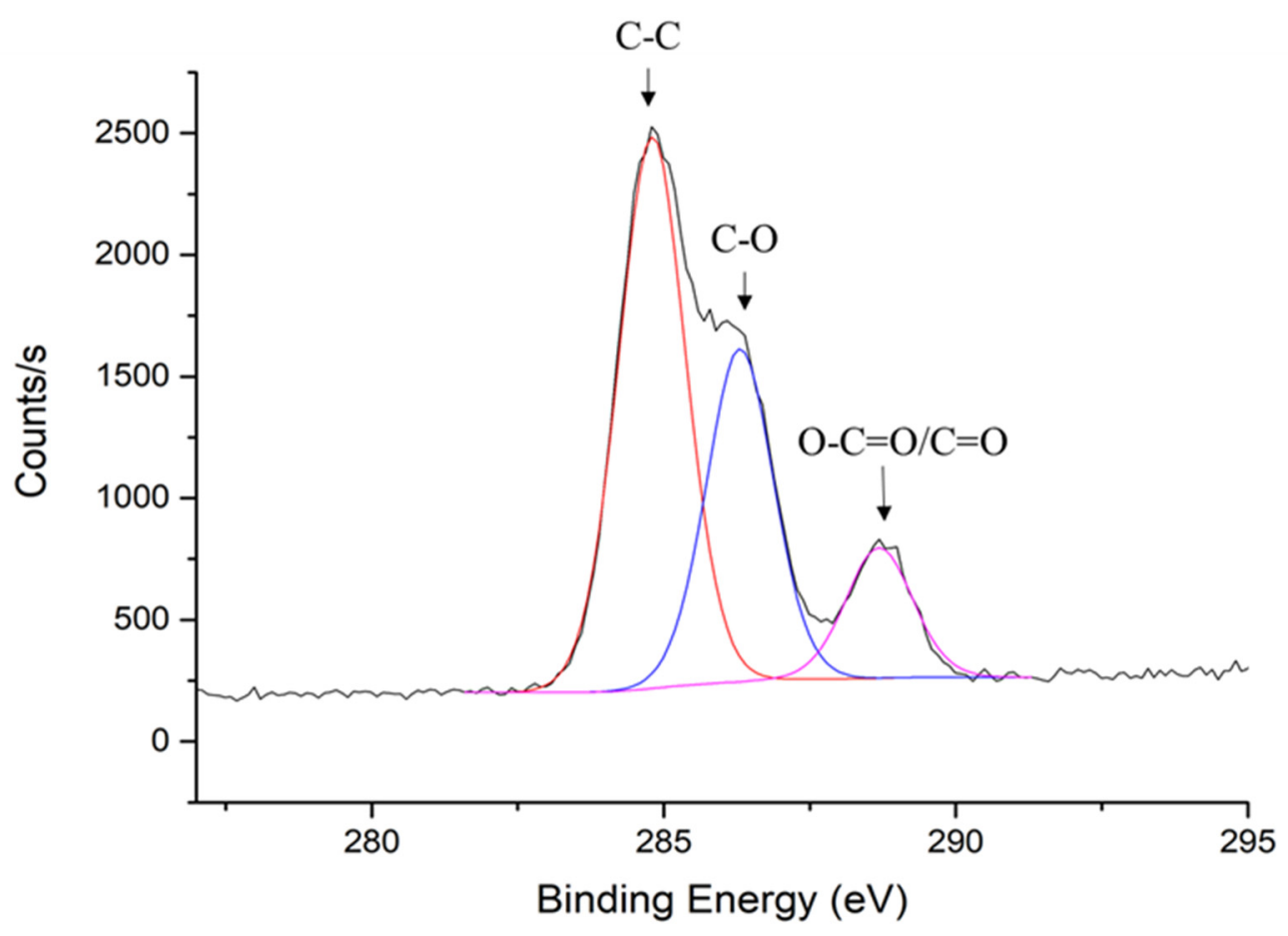

(b)

Figure 5. Carbon analysis of (a) Original sample; (b) After treatment B. 


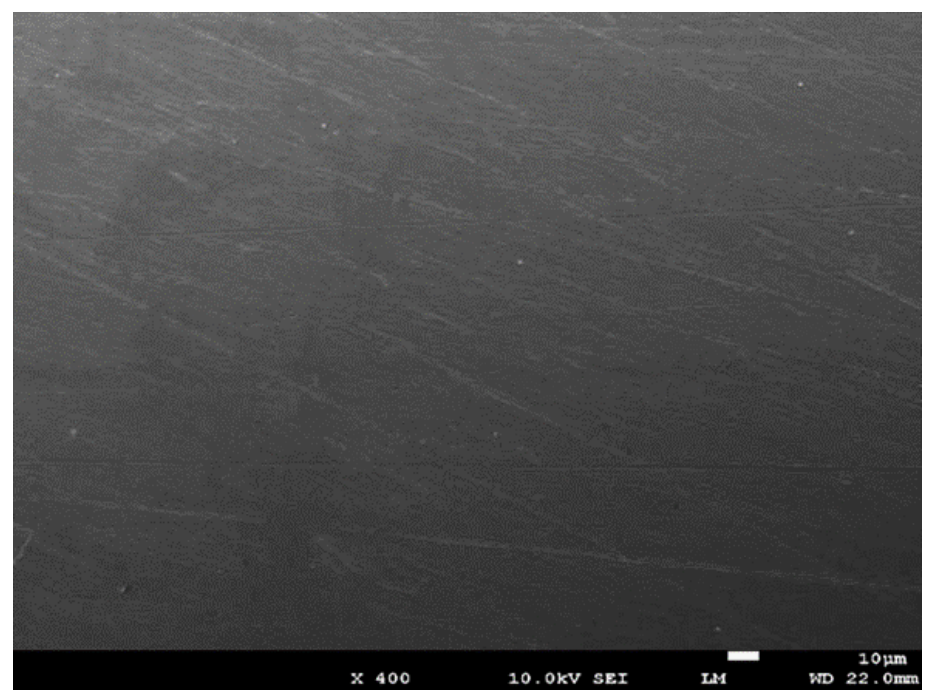

Figure 6. SEM image of the polished sample.

Table 5. XPS analysis of polished sample.

\begin{tabular}{cccc}
\hline \multicolumn{4}{c}{ Atomic Concentration (\%) } \\
\hline $\mathrm{O} 1 \mathrm{~s}$ & $\mathrm{Ag} \mathrm{3d}$ & $\mathrm{C} 1 \mathrm{~s}$ & $\mathrm{Cl} 2 \mathrm{p}$ \\
$12.0 \pm 13.1$ & $39.5 \pm 2.1$ & $46.1 \pm 1.9$ & $2.4 \pm 8.2$ \\
\hline
\end{tabular}

\section{Conclusions}

In this paper, we introduced a novel post-treatment method to increase the performance of the aerosol jet printed electric circuit. Original electric resistance was measured to be $236 \mathrm{~m} \Omega$, after 100 cycles treatment with temperature varied from $-45{ }^{\circ} \mathrm{C}$ to $85{ }^{\circ} \mathrm{C}$, the resistance changed a bit to $230 \mathrm{~m} \Omega$. Meanwhile, after treatment at $80{ }^{\circ} \mathrm{C}$ with $80 \%$ humidity for $120 \mathrm{~h}$, the resistance was successfully reduced to $47 \mathrm{~m} \Omega$. SEM examination showed the surface microstructure remained as the same original structure before and after treatment. XPS analysis showed the silver metal was oxidized after treatment and the carbon element was significantly increased, particularly in the C-C bond. The oxidation of silver surface was due to the presence of a high humidity environment, while the carbon element increase was most probably due to the organic contamination in the atmosphere during the treatment process. A carbon layer was formed on the sample surface, thus resulting in the reduction of electrical resistance. For further investigation, the top few layers of the treated sample were removed by a polishing method. After polishing, the sample resistance increased back to $242 \mathrm{~m} \Omega$, which was near to its original resistance. XPS measurement showed that after the polishing, the surface chemistry changed near to the original surface. The carbon layer formed on surface was removed, thus the sample's conductivity returned to its origin. The findings and proposed treatment method have potential usage as carbon protection coating of electronic devices and enable the printing of high-performance electronic devices.

Overall, the current investigation is a preliminary research that is limited to the discussion of the effect of the surface carbon layer and the related electrical circuit conductivity. To be specific, the proposed post-treatment approach would be beneficial to achieve the high electrical performance while minimizing the electrical resistance. For future work, efforts are required to study the influences of sintering parameters, i.e., sintering temperature and time, on the defect, microstructure, and conductivity of printed sensors.

Author Contributions: Conceptualization, S.K.M., B.L. and J.K.; methodology, S.K.M., B.L. and J.K.; investigation, B.W. and J.P.C.; data curation, B.W. and B.L.; writing-original draft preparation, B.W. and H.Z.; writing-review and editing, B.W., H.Z., J.P.C., and S.K.M.; supervision, S.K.M.; project administration, S.K.M.; funding acquisition, S.K.M., B.L., and J.K. All authors have read and agreed to the published version of the manuscript. 
Funding: This research was supported by a grant from Samsung Electronics, the Singapore Centre for 3D Printing (SC3DP), the National Research Foundation, Prime Minister's Office, Singapore under its Medium-Sized Centre funding scheme.

Acknowledgments: The authors thank Khadka Indira from Nanyang Technological University for help on the SEM testing.

Conflicts of Interest: The authors declare no conflict of interest.

\section{References}

1. Calvert, P. Inkjet Printing for Materials and Devices. Chem. Mater. 2001, 13, 3299-3305. [CrossRef]

2. Singh, M.; Haverinen, H.M.; Dhagat, P.; Jabbour, G.E. Inkjet Printing-Process and Its Applications. Adv. Mater. 2010, 22, 673-685. [CrossRef] [PubMed]

3. Seifert, T.; Sowade, E.; Roscher, F.; Wiemer, M.; Gessner, T.; Baumann, R.R. Additive Manufacturing Technologies Compared: Morphology of Deposits of Silver Ink Using Inkjet and Aerosol Jet Printing. Ind. Eng. Chem. Res. 2015, 54, 769-779. [CrossRef]

4. Najmon, J.C.; Raeisi, S.; Tovar, A. Review of Additive Manufacturing Technologies and Applications in the Aerospace Industry. In Additive Manufacturing for the Aerospace Industry; Froes, F., Boyer, R., Eds.; Elsevier: Amsterdam, The Netherlands, 2019; pp. 7-31.

5. Dilberoglu, U.M.; Gharehpapagh, B.; Yaman, U.; Dolen, M. The Role of Additive Manufacturing in the Era of Industry 4.0. Procedia Manuf. 2017, 11, 545-554. [CrossRef]

6. Yuan, S.; Shen, F.; Chua, C.K.; Zhou, K. Polymeric composites for powder-based additive manufacturing: Materials and applications. Prog. Polym. Sci. 2019, 91, 141-168. [CrossRef]

7. Krebs, F.C. Polymer solar cell modules prepared using roll-to-roll methods: Knife-over-edge coating, slot-die coating and screen printing. Sol. Energy Mater. Sol. Cells 2009, 93, 465-475. [CrossRef]

8. Chen, B.; Jiang, Y.; Tang, X.; Pan, Y.; Hu, S. Fully Packaged Carbon Nanotube Supercapacitors by Direct Ink Writing on Flexible Substrates. ACS Appl. Mater. Interfaces 2017, 9, 28433-28440. [CrossRef]

9. Sirringhaus, H.; Kawase, T.; Friend, R.H.; Shimoda, T.; Inbasekaran, M.; Wu, W.; Woo, E.P. High-Resolution Inkjet Printing of All-Polymer Transistor Circuits. Science 2000, 290, 2123-2126. [CrossRef]

10. Jones, C.S.; Lu, X.; Renn, M.; Stroder, M.; Shih, W.-S. Aerosol-jet-printed, high-speed, flexible thin-film transistor made using single-walled carbon nanotube solution. Microelectron. Eng. 2010, 87, 434-437. [CrossRef]

11. Shaheen, S.E.; Radspinner, R.; Peyghambarian, N.; Jabbour, G.E. Fabrication of bulk heterojunction plastic solar cells by screen printing. Appl. Phys. Lett. 2001, 79, 2996-2998. [CrossRef]

12. Pardo, D.A.; Jabbour, G.E.; Peyghambarian, N. Application of Screen Printing in the Fabrication of Organic Light-Emitting Devices. Adv. Mater. 2000, 12, 1249-1252. [CrossRef]

13. Zhang, H.; Moon, S.K.; Ngo, T.H. 3D Printed Electronics of Non-contact Ink Writing Techniques: Status and Promise. Int. J. Precis. Eng. Manuf. Technol. 2019, 7, 511-524. [CrossRef]

14. Min, K.; Kim, H.-C.; Choi, J.-W.; Lee, I.H. A review on 3D printed smart devices for 4D printing. Int. J. Precis. Eng. Manuf. Technol. 2017, 4, 373-383. [CrossRef]

15. Park, S.-I.; Quan, Y.-J.; Kim, S.-H.; Kim, H.; Kim, S.; Chun, D.-M.; Lee, C.S.; Taya, M.; Chu, W.-S.; Ahn, S.-H. A review on fabrication processes for electrochromic devices. Int. J. Precis. Eng. Manuf. Technol. 2016, 3, 397-421. [CrossRef]

16. Wilkinson, N.J.; Smith, M.A.A.; Kay, R.W.; Harris, R.A. A review of aerosol jet printing-A non-traditional hybrid process for micro-manufacturing. Int. J. Adv. Manuf. Technol. 2019, 105, 4599-4619. [CrossRef]

17. Smith, M.; Choi, Y.S.; Boughey, C.; Kar-Narayan, S. Controlling and assessing the quality of aerosol jet printed features for large area and flexible electronics. Flex. Print. Electron. 2017, 2, 015004. [CrossRef]

18. Zhang, H.; Moon, S.K.; Ngo, T.H. Hybrid Machine Learning Method to Determine the Optimal Operating Process Window in Aerosol Jet 3D Printing. ACS Appl. Mater. Interfaces 2019, 11, 17994-18003. [CrossRef]

19. Clifford, B.; Beynon, D.; Phillips, C.; Deganello, D. Printed-Sensor-on-Chip devices-Aerosol jet deposition of thin film relative humidity sensors onto packaged integrated circuits. Sens. Actuators B Chem. 2018, 255, 1031-1038. [CrossRef]

20. Cantù, E.; Tonello, S.; Abate, G.; Uberti, D.; Sardini, E.; Serpelloni, M. Aerosol Jet Printed 3D Electrochemical Sensors for Protein Detection. Sensors 2018, 18, 3719. [CrossRef] 
21. Cao, C.; Andrews, J.B.; Franklin, A.D. Completely Printed, Flexible, Stable, and Hysteresis-Free Carbon Nanotube Thin-Film Transistors via Aerosol Jet Printing. Adv. Electron. Mater. 2017, 3, 1700057. [CrossRef]

22. Maiwald, M.; Werner, C.; Zoellmer, V.; Busse, M.L. INKtelligent printed strain gauges. Sens. Actuators A Phys. 2010, 162, 198-201. [CrossRef]

23. Zhao, D.; Liu, T.; Zhang, M.; Liang, R.; Wang, B. Fabrication and characterization of aerosol-jet printed strain sensors for multifunctional composite structures. Smart Mater. Struct. 2012, 21, 115008. [CrossRef]

24. Rahman, T.; Moser, R.; Zbib, H.M.; Ramana, C.V.; Panat, R. 3D printed high performance strain sensors for high temperature applications. J. Appl. Phys. 2018, 123, 024501. [CrossRef]

25. Yang, H.; Leow, W.R.; Chen, X. 3D Printing of Flexible Electronic Devices. Small Methods 2018, 2, 1700259. [CrossRef]

26. Mahajan, A.; Frisbie, C.D.; Francis, L.F. Optimization of Aerosol Jet Printing for High-Resolution, High-Aspect Ratio Silver Lines. ACS Appl. Mater. Interfaces 2013, 5, 4856-4864. [CrossRef]

27. Binder, S.; Glatthaar, M.; Rädlein, E. Analytical Investigation of Aerosol Jet Printing. Aerosol Sci. Technol. 2014, 48, 924-929. [CrossRef]

28. Bourassa, J.; Ramm, A.; Feng, J.Q.; Renn, M.J. Water vapor-assisted sintering of silver nanoparticle inks for printed electronics. SN Appl. Sci. 2019, 1, 517. [CrossRef]

29. Efimov, A.; Minkov, K.N.; Arsenov, P.V.; Protas, N.V.; Ivanov, V.V. Investigation of sintering of silver lines on a heated plastic substrate in the dry aerosol jet printing. J. Phys. Conf. Ser. 2018, 1124, 081041. [CrossRef]

30. Halonen, E.; Viiru, T.; Ostman, K.; Cabezas, A.L.; Mantysalo, M. Oven Sintering Process Optimization for Inkjet-Printed Ag Nanoparticle Ink. IEEE Trans. Compon. Packag. Manuf. Technol. 2012, 3, 350-356. [CrossRef]

31. Hwang, J.Y.; Moon, S.-J. The characteristic variations of inkjet-printed silver nanoparticle ink during furnace sintering. J. Nanosci. Nanotechnol. 2013, 13, 6145-6149. [CrossRef]

32. Weise, D.; Mitra, K.Y.; Sowade, E.; Baumann, R.R. Intense Pulsed Light Sintering of Inkjet Printed Silver Nanoparticle Ink: Influence of Flashing Parameters and Substrate. In MRS Online Proceedings Library Archive; Cambridge University Press: Cambridge, UK, 2015; Volume 1761.

33. Goth, C.; Putzo, S.; Franke, J. Aerosol Jet Printing on Rapid Prototyping Materials for Fine Pitch Electronic Applications. In Proceedings of the 2011 IEEE 61st Electronic Components and Technology Conference (ECTC), Lake Buena Vista, FL, USA, 31 May-3 June 2011; pp. 1211-1216.

34. Cicala, G.; Ognibene, G.; Portuesi, S.; Blanco, I.; Rapisarda, M.; Pergolizzi, E.; Recca, G. Comparison of Ultem 9085 Used in Fused Deposition Modelling (FDM) with Polytherimide Blends. Materials 2018, 11, 285. [CrossRef] [PubMed]

35. Fischer, M.; Schöppner, V. Fatigue Behavior of FDM Parts Manufactured with Ultem 9085. JOM 2017, 69, 563-568. [CrossRef]

36. Gebisa, A.W.; Lemu, H.G. Investigating Effects of Fused-Deposition Modeling (FDM) Processing Parameters on Flexural Properties of ULTEM 9085 using Designed Experiment. Materials 2018, 11, 500. [CrossRef] [PubMed]

37. Jiao, L.; Chua, Z.Y.; Moon, S.K.; Song, J.; Bi, G.; Zheng, H.; Lee, B.; Koo, J. Laser-Induced Graphene on Additive Manufacturing Parts. Nanomaterials 2019, 9, 90. [CrossRef]

38. Kao, H.-L.; Chuang, C.-H.; Chang, L.-C.; Cho, C.-L.; Chiu, H.-C. Inkjet-printed silver films on textiles for wearable electronics applications. Surf. Coat. Technol. 2019, 362, 328-332. [CrossRef]

39. Zhang, H.; Choi, J.P.; Moon, S.K.; Ngo, T.H. A hybrid multi-objective optimization of aerosol jet printing process via response surface methodology. Addit. Manuf. 2020, 33, 101096. [CrossRef]

40. Matikainen, A.; Nuutinen, T.; Itkonen, T.; Heinilehto, S.; Puustinen, J.; Hiltunen, J.; Lappalainen, J.; Karioja, P.; Vahimaa, P. Atmospheric oxidation and carbon contamination of silver and its effect on surface-enhanced Raman spectroscopy (SERS). Sci. Rep. 2016, 6, 37192. [CrossRef]

41. Taylor, C.E.; Garvey, S.D.; Pemberton, J.E. Carbon Contamination at Silver Surfaces: Surface Preparation Procedures Evaluated by Raman Spectroscopy and X-ray Photoelectron Spectroscopy. Anal. Chem. 1996, 68, 2401-2408. [CrossRef]

42. Jagdheesh, R.; Diaz, M.; Marimuthu, S.; Ocaña, J. Hybrid laser and vacuum process for rapid ultrahydrophobic Ti-6Al-4 V surface formation. Appl. Surf. Sci. 2019, 471, 759-766. [CrossRef]

43. Kietzig, A.-M.; Hatzikiriakos, S.G.; Englezos, P. Patterned Superhydrophobic Metallic Surfaces. Langmuir 2009, 25, 4821-4827. [CrossRef] 
44. Yang, Z.; Zhu, C.; Zheng, N.; Le, D.; Zhou, J. Superhydrophobic Surface Preparation and Wettability Transition of Titanium Alloy with Micro/Nano Hierarchical Texture. Materials 2018, 11, 2210. [CrossRef] [PubMed]

45. Yang, Z.; Liu, X.; Tian, Y. Insights into the wettability transition of nanosecond laser ablated surface under ambient air exposure. J. Colloid Interface Sci. 2019, 533, 268-277. [CrossRef] [PubMed]

46. Boinovich, L.B.; Emelyanenko, A.; Emelyanenko, K.; Domantovsky, A.; Shiryaev, A. Comment on "Nanosecond laser textured superhydrophobic metallic surfaces and their chemical sensing applications" by Duong V. Ta, Andrew Dunn, Thomas J. Wasley, Robert W. Kay, Jonathan Stringer, Patrick J. Smith, Colm Connaughton, Jonathan D. Shephard (Appl. Surf. Sci. 357 (2015) 248-254). Appl. Surf. Sci. 2016, 379, 111-113. [CrossRef]

47. Wang, B.; Lam, Y.C.; Zheng, H.; Wang, X. Femtosecond laser-induced surface wettability modification of polystyrene surface. Sci. China Ser. G Phys. Mech. Astron. 2016, 59, 124211. [CrossRef]

48. Ngo, C.-V.; Chun, D.-M. Fast wettability transition from hydrophilic to superhydrophobic laser-textured stainless steel surfaces under low-temperature annealing. Appl. Surf. Sci. 2017, 409, 232-240. [CrossRef]

49. Lian, Z.; Xu, J.; Yu, Z.; Yu, P.; Ren, W.; Wang, Z.; Yu, H. Bioinspired Reversible Switch between Underwater Superoleophobicity/Superaerophobicity and Oleophilicity/Aerophilicity and Improved Antireflective Property on the Nanosecond Laser-Ablated Superhydrophobic Titanium Surfaces. ACS Appl. Mater. Interfaces 2019, 12, 6573-6580. [CrossRef]

50. Chang, F.-M.; Cheng, S.L.; Hong, S.-J.; Sheng, Y.-J.; Tsao, H.-K. Superhydrophilicity to superhydrophobicity transition of CuO nanowire films. Appl. Phys. Lett. 2010, 96, 114101. [CrossRef]

51. Ta, D.V.; Dunn, A.K.; Wasley, T.J.; Kay, R.W.; Stringer, J.; Smith, P.J.; Connaughton, C.; Shephard, J.D. Nanosecond laser textured superhydrophobic metallic surfaces and their chemical sensing applications. Appl. Surf. Sci. 2015, 357, 248-254. [CrossRef]

52. Long, J.; Zhong, M.; Zhang, H.; Fan, P. Superhydrophilicity to superhydrophobicity transition of picosecond laser microstructured aluminum in ambient air. J. Colloid Interface Sci. 2015, 441, 1-9. [CrossRef]

53. Long, J.; Zhong, M.; Fan, P.; Gong, D.; Zhang, H. Wettability conversion of ultrafast laser structured copper surface. J. Laser Appl. 2015, 27, S29107. [CrossRef]

54. Liu, W.; Cai, M.; Luo, X.; Chen, C.; Pan, R.; Zhang, H.; Zhong, M. Wettability transition modes of aluminum surfaces with various micro/nanostructures produced by a femtosecond laser. J. Laser Appl. 2019, 31, 022503. [CrossRef]

55. Boinovich, L.B.; Emelyanenko, A.M.; Modestov, A.D.; Domantovsky, A.G.; Emelyanenko, K.A. Synergistic Effect of Superhydrophobicity and Oxidized Layers on Corrosion Resistance of Aluminum Alloy Surface Textured by Nanosecond Laser Treatment. ACS Appl. Mater. Interfaces 2015, 7, 19500-19508. [CrossRef] [PubMed]

56. Yan, H.; Rashid, M.R.B.A.; Khew, S.Y.; Li, F.; Hong, M. Wettability transition of laser textured brass surfaces inside different mediums. Appl. Surf. Sci. 2018, 427, 369-375. [CrossRef]

57. Lee, J.; Shin, S.; Kang, S.; Lee, S.; Seo, J.; Lee, T. Highly Stable Surface-Enhanced Raman Spectroscopy Substrates Using Few-Layer Graphene on Silver Nanoparticles. J. Nanomater. 2015, 2015, 1-7. [CrossRef]

58. Sun, Z.; Yan, Z.; Yao, J.; Beitler, E.; Zhu, Y.; Tour, J.M. Growth of graphene from solid carbon sources. Nat. Cell Biol. 2010, 468, 549-552. [CrossRef]

Publisher's Note: MDPI stays neutral with regard to jurisdictional claims in published maps and institutional affiliations.

(C) 2020 by the authors. Licensee MDPI, Basel, Switzerland. This article is an open access article distributed under the terms and conditions of the Creative Commons Attribution (CC BY) license (http://creativecommons.org/licenses/by/4.0/). 